Canadian

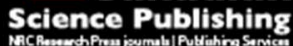

Applied Physiology, Nutrition, and Metabolism Physiologie appliquée, nutrition et métabolisme

\title{
CARBOHYDRATE SUPPLEMENTATION ATTENUATES DECREMENT OF PERFORMANCE IN OVERTRAINED RATS
}

\begin{tabular}{|r|l|}
\hline Journal: & Applied Physiology, Nutrition, and Metabolism \\
\hline Manuscript ID & apnm-2015-0393.R1 \\
\hline Manuscript Type: & Article \\
\hline Date Submitted by the Author: & O4-Sep-2015 \\
\hline Complete List of Authors: & $\begin{array}{l}\text { Oliveira Coutinho de, Caio; Federal University of Paraíba, Nutrition } \\
\text { Departament } \\
\text { Barbosa, Carlos; Federal University of Paraíba, Nutrition Department } \\
\text { Massa, Nayara; Federal University of Paraíba, Nutrition Department } \\
\text { Pereira, Reabias; Federal University of Paraíba, Physical Education } \\
\text { Department } \\
\text { Félix, Gustavo; Federal University of Paraíba, Physical Education } \\
\text { Department } \\
\text { Aquino, Jailane; University Federal of Paraíba, Nutrition Departament } \\
\text { Oliveira, Edilamar; University of São Paulo, Biodynamic of the Movement of } \\
\text { the Human Body Department } \\
\text { Silva, Alexandre; University Federal of Paraíba, Department of Physical } \\
\text { Education }\end{array}$ \\
\hline Keyword: & $\begin{array}{l}\text { Carbohydrate, exercise < exercise, performance < performance, } \\
\text { Overtraining, Akt-1 }\end{array}$ \\
\hline
\end{tabular}


1 CARBOHYDRATE SUPPLEMENTATION ATTENUATES DECREMENT OF

2 PERFORMANCE IN OVERTRAINED RATS

3

4 Caio Victor Coutinho de Oliveira, Carlos Vinícius Barbosa, Nayara Moreira Massa, Reabias

5 de Andrade Pereira, Gustavo da Silva Félix, Jailane de Souza Aquino, Edilamar Menezes de

6 Oliveira, Alexandre Sérgio Silva.

8 C.V. Oliveira; C.V. Barbosa; N.M. Massa; J.S. Aquino. Nutrition Department, Federal

9 University of Paraíba, ZIP CODE 58051-900, João Pessoa, Paraíba, Brazil. E-mail:

caiovco@gmail.com; cv_vinicius17@hotmail.com; nayaramassa@hotmail.com;

11 lalaaquino@hotmail.com. gustavoofelix@gmail.com; São Paulo, ZIP CODE 05508900 São Paulo, São Paulo, Brazil. E-mail: edilamar@usp.br.

Corresponding Author: A.S. Silva. Physical Education Department, Federal University of Paraíba, João Pessoa, Paraíba, Brazil. R. Silvino Lopes, 410 / 804, Tambaú - João Pessoa/Paraíba, Brazil. ZIP CODE: 58.039-190. E-mail: alexandresergiosilva@yahoo.com.br. Phone: 5583 8875-4675

.

R.A. Pereira; G.S. Félix. Physical Education Department, Federal University of Paraíba, ZIP CODE 58051-900, João Pessoa, Paraíba, Brazil. E-mail: reabiasedf@gmail.com;

E.M. Oliveira. Biodynamic of the Movement of the Human Body Department, University of 


\section{Abstract}

27 Although carbohydrate ingestion at the end of single exercises is recognized to delays fatigue 28 and accelerates recovery, if chronic ingestion can prevent overtraining during periods of 29 intense training is something not yet elucidated. The present study aimed to determine 30 whether carbohydrate supplementation minimize overtraining in Wistar rats. The animals 31 underwent 11 weeks of training (running) on a treadmill, and the last 3 weeks were designed 32 to induce overtraining. One group was supplemented with carbohydrates (EX-CHO; $n=13)$, 33 one group had no supplementation $(\mathrm{EX} ; \mathrm{n}=10)$, and another group remained inactive $(\mathrm{C}$; $34 \mathrm{n}=9)$. Performance tests $(\operatorname{Pr})$ were given before training $(\operatorname{Pr} 1)$ and at the $8^{\text {th }}(\operatorname{Pr} 2)$ and $11^{\text {th }}$ 35 training week (Pr3). Food intake, body weight, testosterone, cortisol, malondialdehyde, 36 creatine kinase (CK) and activities of PI3-K, Akt-1, mTOR and GSK-3 enzymes were 37 measured. In the EX group, there was a significant $32.6 \%$ performance decrease at $\operatorname{Pr} 3$ 38 compared to Pr2. Additionally, at protocol completion, the EX-CHO group had a greater 39 gastrocnemius weight than the $\mathrm{C}$ group $(\mathrm{p}=0.02)$, which did not occur in the EX group. 40 Training caused anorexia, decreased testosterone $(\mathrm{p}=0.001)$ and increased malondialdehyde $41(\mathrm{p}=0.009)$ in both exercise groups compared to $\mathrm{C}$, without an influence of carbohydrate 42 supplementation on these variables $(p>0.05)$. The activity of Akt-1 was higher in the EX$43 \mathrm{CHO}$ group but not the EX group compared to the $\mathrm{C}$ group $(\mathrm{p}=0.013)$. Carbohydrate 44 supplementation promoted an attenuation in the performance decrement and maintained 45 gastrocnemius muscle mass in animals that had undergone overtraining protocols, which was accompanied by increased activity of the Akt-1 molecular indicator.

47 Keywords: Carbohydrate, Exercise, Performance, Overtraining, Akt-1, Rats. 
49

50

51

52

53

\section{Introduction}

Overtraining syndrome (OTS) is a phenomenon that has increased in prevalence among high-performance athletes (Smith 2000). It is estimated that 37\% of elite athletes from various sports have suffered from OTS symptoms at some point in their careers (Kenttä et al. 2001), specifically, 65\% of distance runners (Morgan et al. 1987), 50\% of semi-professional soccer players and $21 \%$ of swimmers on the Australian national team (Smith 2000).

OTS results from an imbalance between excess training and inadequate recovery (Armstrong and VanHeest 2002). Nutrition participates in the etiology of OTS, as nutrients strongly influence the recovery time between exercise sessions (Kreider 2010) and provide energy to muscles during subsequent training sessions. In this sense, the use of nutritional resources to accelerate post workout recovery has grown considerably (Mitchell 2013).

Among various nutritional resources, carbohydrates are recognized as a very important effective ergogenic aid. Supplementation has been shown to be effective in delaying fatigue in prolonged exercise (Borges et al. 2012), increasing the rate of glycogen resynthesis (Van Loon et al. 2000), accelerating the recovery of physical capacity (De Sousa, et al. 2010) and elevating insulinemia during exercise (McAnulty et al. 2007). As carbohydrates are capable of accelerating post-exercise recovery, this phenomenon supports the hypothesis that carbohydrate supplementation can minimize or prevent the development of OT over a season of intense training. However, most studies that have provided support for this hypothesis have done so only after one or few sessions (De Sousa et al. 2010; Karelis et al. 2010) and it is not wise to extrapolate the ergogenic effect of carbohydrates to a whole training season.

The only investigations that have tested the chronic effects of carbohydrates on the prevention of OT were conducted with cyclists (Halson et al. 2004) and runners (Achten et al 
74 2004). However, these interventions lasted less than 11 days and had short recovery intervals.

75 Thus, we believe that this short intervention precludes the prevention premise within a more 76 chronic context, as OT is most often experienced.

77 Thus, this study was conducted to assess the influence of carbohydrate 78 supplementation on the prevention or minimization of overtraining in an experimental animal 79 model of intense physical training with short recovery intervals. The aim of this study was to 80 assess whether carbohydrate supplementation can prevent or minimize OT in adult male 81 Wistar rats by observing a performance test, which is the main indicator OT (Smith 2000). In 82 addition, we aimed to assess whether changes in enzymatic OT markers, hormonal OT 83 markers, oxidative stress and the activity of enzymes involved in the muscular 84 anabolism/catabolism process are involved in the possible protective effects of carbohydrates 85 in OT.

\section{$87 \quad 2$ Materials and Methods}

Animals: A total of 32 Wistar male rats (Rattus norvegicus albinus) were used; they were 12 weeks old and procured from the "Professor Dr. Thomas Georgel" vivarium at the

91 Biotechnology Center (CBiotec), Federal University of Paraíba (UFPB). The rats were 92 divided into three groups: Sedentary control $(\mathrm{C}: \mathrm{n}=9)$; exercise group without 93 supplementation $(\mathrm{EX}: \mathrm{n}=10)$ and exercise group supplemented with carbohydrates (EX94 CHO: $\mathrm{n}=13$ ). Animals were kept under standard lighting conditions (light/dark cycle, 12/12 hours); the environment was kept at $22 \pm 1^{\circ} \mathrm{C}$ and $65 \%$ humidity, and they were housed in 96 groups of five. They received fresh water and food daily ad libitum. The procedures were in

97 accordance with the laboratory animals' handling and care principles recommended by the 98 Brazilian College of Animal Experimentation (COBEA). The research project was approved 
99 by the Ethics Committee on Animal Use (CEUA) - UFPB under the protocol number $100 \quad 1303 / 12$

101

Adaptation to training and gavage: Rats underwent two weeks of adaptation to the gavage procedure and treadmill running. They were subjected to running 10 minutes per day at a speed of $12 \mathrm{~m} / \mathrm{min}$ five consecutive days per week. Using a scale described by Lira et al. (2010) the animals were ranked on a daily basis according to the behavior during the treadmill session: 1) refuses to run; 2) below average runner (runs and stops; runs in the wrong direction); 3) average runner; 4) above average runner (runs constantly, occasionally running below the treadmill speed); and 5) good runner (runs consistently at the treadmill speed). Animals that had an average of 3 or more $(n=32)$ were included in the study. After the exercise, they underwent a process of gavage with water.

Training protocol: The training protocol started the very next week after adaptation. It was performed according to the previously characterized procedure to induce overtraining in Wistar rats by Hohl et al. (2009). The first stage (T1) consisted of four weeks of running at speeds varying from 15 to $25 \mathrm{~m} / \mathrm{min}$ and lasting 25 to 60 minutes five consecutive days per week. In the second phase (T2), which was four weeks long, we kept the same running speed and session's duration that were achieved at the end of T1, also five consecutive days per week. Stages T1 and T2 were performed between 01:00PM and 05:00PM. The third and final training stage (T3) lasted three weeks and was characterized by an increased frequency of training to up to four sessions per day. As the number of daily sessions increased, the recovery time between sessions was reduced from 4 hours to 3 hours and then to 2 hours. The last session of the day always ended at 05:00PM. 
123 Performance Tests (Pr): Performance tests were performed 48 hours after the adaptation 124 period, during the $8^{\text {th }}$ week of training and during the $11^{\text {th }}$ week of training (always between $125 \quad 01: 00 \mathrm{PM}$ and 05:00PM). After the performance test, the rats were allowed 48 hours of rest in 126 order to recover before the next week of training. Tests started with animals running on a 127 treadmill without an incline and an initial speed of $12 \mathrm{~m} / \mathrm{min}$ for five minutes. Then, the 128 speed was increased $2 \mathrm{~m} /$ min every 3 minutes until exhaustion, which was defined when the 129 animals could not maintain the speed despite being encouraged three times by researchers. 130 Performance was quantified with an equation described by Hohl et al. (2009). By considering all the forces proportional to body weight and all the speeds proportional to the running speed, mechanical energy becomes proportional to mass $\times$ speed. This assumption allows one to measure the rat's performance with a quantity that is proportional to the mechanical work, i.e., force $\times$ duration, as shown in the equation below.

$$
\operatorname{Pr}=\sum P r i=\sum m V i T i=\sum m D i=m D
$$

where $\operatorname{Pr}=$ rat's performance in kilograms - meters $(\mathrm{Kg} . \mathrm{m})$; Pri = rat's performance in each stage, $\mathrm{m}=$ body mass index $; \mathrm{Vi}=$ stage speed; $\mathrm{Ti}=$ running time in each stage $; \mathrm{Di}=$ distance achieved in the stage; and $\mathrm{D}=$ total distance covered on the test.

140 The procedures performed throughout the experimental protocol for induction of overtraining 141 are described in figure 1. 
Supplementation Protocol: Solutions with 30\% carbohydrate in the form of dextrose were administered to the animals by gavage before and immediately after each exercise session during the $9^{\text {th }}$ week and on the $1^{\text {st }}$ and $3^{\text {rd }}$ exercise session of each one of the $10^{\text {th }}$ and $11^{\text {th }}$ weeks. The dose was $1.0 \mathrm{~mL}$ per $100 \mathrm{~g}$ body weight, as described by Morifuji et al. (2010) and Morifuji et al. (2011).

Animals Sacrifice: Exactly 36 hours after the last performance test and after a 12-hour fast, the animals were intraperitoneally anesthetized with ketamine $(75 \mathrm{mg} / \mathrm{kg})$ and xylazine (20 $\mathrm{mg} / \mathrm{kg}$ ). Subsequently, they were sacrificed by exsanguination according to the Brazilian College of Animal Experimentation (COBEA) ethical principles.

Biochemical analyses: Blood was collected by cardiac puncture and placed in test tubes with and without EDTA. Then, the samples were centrifuged at 3,000 rpm for 15 minutes and stored at $-80^{\circ} \mathrm{C}$ until analysis. Biochemical assays were performed on serum creatine kinase (CK) using a commercial kit (Labtest, Minas Gerais, Brazil) and on testosterone and cortisol by chemiluminescence using an automatic biochemical analyzer Elecsys 2010 (Roche). With plasma samples, malondialdehyde (MDA) was determined.

Protein activity of GSK-3, PI3-K, Akt-1 and mTOR: The gastrocnemius muscle was homogenized in hypotonic lysis buffer containing $50 \mathrm{mM}$ potassium phosphate $(\mathrm{pH} 7.0), 0.3$ M sucrose, 0.5 mM DTT, $1 \mathrm{mM}$ EDTA ( $\mathrm{pH} 8.0), 0.3 \mathrm{mM}$ PMSF, $10 \mathrm{mM} \mathrm{NaF}$, and a cocktail of protease and phosphatase inhibitors (1:100). The homogenate was centrifuged at 12,000 rpm for 10 minutes at $4^{\circ} \mathrm{C}$, transferred to $1.5 \mathrm{ml}$ tubes and stored at $-80^{\circ} \mathrm{C}$. The protein concentration was determined using the Bradford method (1976) (Bradfort 1976). 
Aliquots $(30 \mathrm{mg})$ of the homogenate were diluted in sample buffer (Tris-HCl, 240

$172 \mathrm{mM}(\mathrm{pH}$ 6.8), $0.8 \%$ SDS, $200 \mathrm{mM} \quad \beta$-mercaptoethanol, $40 \%$ glycerol and $0.02 \%$

173 bromophenol blue). The analysis of protein levels was performed with western blotting using

174 polyacrylamide gel electrophoresis (SDS-PAGE 6-12\%, depending on the protein molecular

175 weight) (Towbin 1992). Subsequently, proteins were transferred to a nitrocellulose membrane

176 (Amersham Biosciences, Piscataway, NJ, USA) and incubated with casein and PI3K

177 p110alpha primary antibodies (rabbit polyclonal, 1:1000, Santa Cruz, CA, USA), Akt1

178 (rabbit polyclonal, 1:1000, Santa Cruz, CA, USA), p-Akt1 (Ser473) (rabbit polyclonal,

179 1:1000, Santa Cruz, CA, USA), mTOR (rabbit polyclonal, 1:1000, Cell Signaling Tech., MA,

180 USA), p-mTOR (Ser2448) (rabbit polyclonal, 1:1000, Cell Signaling Tech., MA, USA),

181 GS3Kb (rabbit polyclonal, 1:1000, Cell Signaling Tech., MA, USA), and p-GS3Kb (Ser9)

182 (rabbit polyclonal, 1:1000, Cell Signaling Tech., MA, USA). Unbound antibody was

183 removed by washing, and the membrane was exposed to the secondary antibody (conjugated

184 to horseradish peroxidase (HRP)), which was directed to species-specific portions of the

185 primary antibody. Then, they were washed 3 times for $10 \mathrm{~min}$ each in TBS-T and incubated

186 for 2 hours with the secondary antibodies (all anti-rabbit, Amersham Biosciences, NJ, USA)

187 conjugated to peroxidase. Subsequently, the complex was detected by

188 electrochemiluminescence (ECL). The protein concentration was normalized to that of

189 glyceraldehyde 3-phosphate dehydrogenase (GAPDH). The images were visualized using the

190 Chemi-doc Gel Quantification System (Bio-Rad, Hercules, CA, USA). Protein concentrations

191 were quantified from the blots using Image J software (Image $\mathrm{J}$ based on NIH image). The

192 ratio of phosphorylated protein/total protein $(\mathrm{P} / \mathrm{T})$ was calculated in order to measure changes

193 in the proteins' activity.

194 
195 Statistical Analyses: Data are presented as the mean and standard deviation. The Shapiro-

196 Wilk and Levene tests were initially performed in order to verify normality and compare 197 differences between the variables' standard deviations. We used analysis of variance (two198 way or one-way ANOVA, as appropriate) with Tukey's post hoc test or, for a non-parametric 199 USA).

203

\section{Results}

205 trend towards higher performance in the EX-CHO group $(p=0.063)$. 
220 Food Consumption: The three groups maintained similar food consumption during the first

221 eight weeks of training (Figure 3). While the animals that remained sedentary consumed the

222

223

224

225

226

\section{Insert Figure 3}

Mass of Animals, Organs and Peritoneal Fat: The rats in all three groups maintained a similar body weight until the $8^{\text {th }}$ week (data not shown). Then, the animals that underwent the overtraining protocol achieved a lower body weight compared to the $C$ group $(p<0.001)$. The rats in the exercise groups also exhibited a lower amount of absolute peritoneal fat and peritoneal fat corrected for body weight $(\mathrm{p}<0.001)$. There were no differences between the EX and EX-CHO groups. (Table 1), although EX-CHO teham completed the protocol with body weight $2 \%$ higher than EX group.

\section{Insert Table 1}


Trained animals presented a reduction in gastrocnemius weight compared to the $\mathrm{C}$ group $(p<0,001)$ with no differences between groups $(p>0,05)$. However, when the gastrocnemius weight was corrected for body weight, an inverse behavior was observed so that the weight of this muscle in the EX-CHO group was significantly higher than in the $\mathrm{C}$ group $(\mathrm{p}<0.05)$. The normalized gastrocnemius muscle mass of the rats in the EX group was not significantly different than that of the $\mathrm{C}$ group.

The animals in the three groups presented exactly the same thymus weight in the $8^{\text {th }}$ week. At the end of the experimental protocol, the trained animals presented a significantly lower thymus weight in relation to the $\mathrm{C}$ group. When comparing only the trained animals, it was noted that carbohydrate supplementation exerted a protection against the reduction of thymus weight. Indeed, the animals in the EX-CHO group presented a significantly greater thymus weight in relation to animals in the EX group. This same behavior was reproduced in the analysis of thymus weight corrected for body weight.

Biochemical analyses: Parameters related to hormones, muscle damage and oxidative stress at the end of the experimental protocol are described in Table 2. Concentrations of creatine completed the experiment with similar results. 
269 Molecular Aspects: Analyses of the activities of muscle proteins related to glycogen 270 synthesis and protein synthesis are shown in Figure 4. Training led to an increase in GS3Kb 271 activity compared to the C group $(\mathrm{p}<0.01)$, but no differences were noted between the EX 272 and EX-CHO groups, although EX-CHO has finished protocol with values 8\% lower than 273 EX. Similarly, PI3K was more active in the EX and EX-CHO groups $(\mathrm{p}<0.001)$ compared to 274 the C group. EX-CHO showed PI3k levels 18\% greater than EX group but without statistical 275 difference noted between these two groups. Meanwhile, Akt-1 presented significantly higher 276 activity in the EX-CHO group compared to the $\mathrm{C}$ group $(\mathrm{p}<0.05)$; however, Akt-1 activity 277 was not greater in the EX group compared to the C group. Contrasting with these results, 278 mTOR activity showed no differences between groups.

\section{Discussion} of gastrocnemius muscle mass which are also indicators of OT, in addition to increased activity of Akt-1. However, the carbohydrates had no influence on several other markers of OT: biochemical markers, hormone activity, oxidative stress, body composition and the activity of other enzymes involved in protein synthesis (besides Akt-1). 
The exercise protocol used to induce OT was based on a previously validated protocol 295 for Wistar rats (Lira et al. 2010). The performance reduction in the performance test 296 confirmed OT occurrence, and this phenomenon was accompanied with deleterious 297 alterations in classical markers of overtraining: a reduction in food consumption, a reduction

in serum testosterone levels and an increase in MDA concentration (Meeusen et al. 2013). In addition to the negative alterations in these markers, the present study also demonstrated thymus atrophy, an indicator of compromised immune activity (Woods et al. 2003) and, in particular, compromised immunity due to stress induced by physical exercise in rats (Sapin et al. 2005; Rogero et al. 2005).

In addition to delaying fatigue by mechanisms involved in glucose metabolism (Mitchell 2013; Coletta et al. 2013; Toone and Betts 2010) carbohydrates prevents exerciseinduced immunosuppression (Walsh et al. 2011), reduces pro-oxidant activity (McAnulty et al. 2007), provides a less catabolic hormonal profile during and after the workout (Gleeson 2006) and promotes a greater rate of glycogen resynthesis after training sessions (Alghannam 2011). Although these effects may directly contribute to prevention of OT, the studies that presented these effects were acute in character, i.e., measurements occurred during a single exercise session or in protocols with two daily exercise sessions. These data do not allow extrapolation to a possible prevention OT over a season of several weeks or months of training, as is the reality for athletes. These phenomena can only be demonstrated with a chronic training and supplementation protocol.

Longer studies have been conducted (Halson et al. 2004; Achten et al. 2004). However, data are insufficient to answer whether carbohydrate supplementation can prevent or minimize OT either because the study was too short (less than 11 days) or because only mood-related variables were evaluated, although an attenuation in the performance decrease has been observed. 
Attenuation in the performance decrement as indicator of overtraining prevention during performance test by carbohydrate supplementation in rats corroborates studies' results with humans (Halson et al. 2004; Achten et al. 2004). In these studies, runners and cyclists who consumed supplemental carbohydrates experienced an attenuation in performance decrease after a strenuous physical training period. However, the protocols lasted only eight or eleven days.

Anorexia is consensually associated with OT. It is an indicator of hypothalamic dysfunction induced by overproduction of cytokines, a phenomenon often observed in the presence of overtraining (Smith 2004). We were not able to quantify the levels of any cytokines, but the observation that supplementation induced a milder anorexic profile is of practical importance, as it alleviates the complications associated with OT-induced anorexia.

Xiao et al. (2012) and Dong et al. (2011) observed inhibition of the growth of the gastrocnemius muscle using the same protocol for OT induction as our study. Similarly, we found that carbohydrate supplementation was able to mitigate this muscle's loss of mass. This protective function of carbohydrates can be attributed to increased glycogen storage due to more food consumption in rats supplemented with carbohydrates. Indeed, muscle glycogen is essential to prevent catabolism from hard physical training (Yan et al. 1992). However, GS enzyme activity was not affected by carbohydrates, despite the observation by Morifuji et al. (2011) who demonstrated that carbohydrate supplementation is associated with higher GS activity and higher glycogen stores. On the other hand, the activity of Akt-1, one of the key enzymes involved in muscle protein synthesis, was increased in supplemented animals, indicating maintenance of anabolic and anti-catabolic activity.

It was expected that the increase in Akt-1 activity was accompanied with a concomitant increase in mTOR enzyme activity, but this did not happen in animals treated with carbohydrates. This result may be due to two reasons: 1) mTOR activation can occur 
344 through an independent pathway through Akt-1, due to the contractile stimulus of exercise 345 (Parkington et al. 2003) and 2) mTOR activation appears to be greater in fiber type IIa, 346 (Deldicque et al. 2005) while the gastrocnemius muscle presents a mixed composition (Song 347 et al. 1963). The activity of FOXO, the primary regulator of muscle catabolism, was not positively to an exercise stimulus, resulting in an improvement in the immune system (Terra et al. 2012). However, in response to chronic and exhausting protocols, these positive effects assessed in this study but may lend more insight into the relationship between carbohydrate supplementation and catabolic/anabolic pathways.

The weight of the lymphoid organs have been used as an indicator of the impact of exercise on the immune system (Woods et al. 2003). Ideally, the lymphoid organs react are minimized (Alghannam 2011). The hindered strengthening of the immune system was confirmed in an experiment in which a 16-week training protocol resulted in thymic atrophy (Woods et al. 2003), suggesting apoptosis from chronic stress. Our data from the two groups of animals subjected to OT also show thymic atrophy. Fortunately, carbohydrate supplementation was able to mitigate this deleterious effect, indicating an ergogenic action of carbohydrates in attenuating the decrease in immunocompetence. The observation of this interesting phenomenon guides prospects for future studies. For example, our data suggest a hypothesis that immune mediators are preserved in response to carbohydrate supplementation in the presence of chronic stress induced by intense and voluminous physical training. Indeed, there is evidence that carbohydrate supplementation preserves immunocompetence in response to single sessions of intense exercise (Gleeson 2006; McAnulty et al. 2007).

It is well established that increased oxidative stress, systemic inflammation and cortisol production as well as reduced plasma concentrations of testosterone are found in the OT state (Hohl et al. 2009; Meeusen et al. 2013). Our data regarding pro-oxidant activity of malondialdehyde and testosterone confirm these previous findings. However, carbohydrate 
369 supplementation was not able to prevent these deleterious effects of OT. Antioxidant activity

370 has been reported for carbohydrates in some studies (Nieman at al. 2005; Scharhag et al.

371 2006). However, all these studies used acute strenuous exercise protocols. Thus, their results

372 can only be cautiously extrapolated to chronic situations. It seems that the large magnitude of

373 oxidative stress caused by strenuous consecutive training that leads to OT surpasses the

374 antioxidant capacity previously reported for post-workout carbohydrates.

375 Taken together, the data from this study demonstrated that carbohydrate

376 supplementation promotes a slight attenuation in the decrease of performance which is the

377 most direct indicate OT, a phenomenon that is accompanied by attenuation of some, but not

378 all others physiological indicators of OT. Although there were no statistical differences

379 found, the EX-CHO group completed the protocol with activity PI3k 18\% higher than the EX

380 group as well as cortisol 9.9\% lower, activity GS3 8\% more body weight and 2\% above the

381 EX group. Accordingly, these variables should not be discarded in future studies. Added to

382 the markers that statistically minimizing OT promoted by carbohydrate (lower decline in

383 physical performance, smaller reduction in food consumption, less loss of lower thymus

384 weight muscle loss), can express more evidently the protection of carbohydrates in

385 minimizing or preventing OT. These data encourage the implementation of studies with

386 athletes undergoing exhaustive training and competition sessions that characterize modern

387 sports competitions.

388 A limitation of the study is the fact that adopted training protocol was the only 389 validated to induce OT in rats. This protocol provides a training frequency that usually is not 390 seen in humans. However, to meet the objectives of the study, we would have to adopt a 391 protocol which will surely promote OT. Therefore, in this study it was found that if the 392 carbohydrates minimizes the OT, so that could not be observed if the carbohydrate prevents 393 the OT. 
394 Considering this study's limitations, we recommend extensions of this study that 395 include measurement of the contents of muscle and liver glycogen, the activity of the muscle 396 catabolic enzyme FOXO, and immunological agents responsive to physical training in 397 animals and, when possible, humans. We also recommend that this study be replicated with 398 more similar training loads to athletes. These data will help elucidate how carbohydrates can 399 prevent or minimize the development of OT syndrome.

400

401

Acknowledgments:

402 Funding sources: National Research Council (CNPq), Federal Government, Brazil.

403 Conflict of Interest: none

404 
$405 \quad 5$ References

406

407

408 Achten, J., Halson, S.L., Moseley, L., Rayson, M.P., Casey, A., and Jeukendrup, A.E. 2004.

409 Higher dietary carbohydrate content during intensified running training results in better

410 maintenance of performance and mood state. J Appl Physiol. 96(4): 1331-40. doi:

$411 \quad$ 10.1152/japplphysiol.00973.2003

412

413 Alghannam, A.F. 2011. Carbohydrate - protein ingestion improves subsequent running 414 capacity towards the end of a football-specific intermittent exercise. Appl Physiol Nutr 415 Metab. 757(36): 748-57. doi: 10.1139/h11-097

416

417 Armstrong, L., and VanHeest, J. 2002. The unknown mechanism of the overtraining 418 syndrome: clues from depression and psychoneuroimmunology. Sport Med. 32(3): 185-209. 419 doi: 10.2165/00007256-200232030-00003

420

421 Borges, G.F., Teixeira, A.M., and Ferreira, J.P. 2012. Meta-análise do efeito no sistema 422 imunitário da suplementação de hidratos de carbono no exercício físico Meta-analysis of the 423 effect on immune system of carbohydrate. Motricidade. 8(2): 83-97. doi: $424 \quad 10.6063 /$ motricidade.8(2).717

425

426 Bradfort, M. 1976. A rapid and sensitive method for the quantitation of microgram quantities 427 of protein utilizing the principle of protein-dye binding. Anal Biochem. 72(1-2): 248-54.

428 doi:10.1016/0003-2697(76)90527-3

429 
430 Coletta, A., Thompson, D.L., and Raynor, H.A. 2013. The influence of commercially431 available carbohydrate and carbohydrate-protein supplements on endurance running 432 performance in recreational athletes during a field trial. J Int Soc Sports Nutr. 10(17): 1-7. 433 doi: $10.1186 / 1550-2783-10-17$

434

De Sousa, M.V., Madsen, K., Simões, H.G., Pereira, R.M.R., Negrão, C.E., Mendonça, R.Z., 436 et al. 2010. Effects of carbohydrate supplementation on competitive runners undergoing overload training followed by a session of intermittent exercise. Eur J Appl Physiol. 109(3): 507-16. doi: 10.1007/s00421-010-1388-8

439

Deldicque, L., Theisen, D., and Francaux, M. 2005. Regulation of mTOR by amino acids and resistance exercise in skeletal muscle. Eur J Appl Physiol. 94(1-2): 1-10. doi: 10.1007/s00421-004-1255-6

Dong, J., Chen, P., Wang, R., Yu, D., Zhang, Y., and Xiao, W. 2011. NADPH oxidase: a 445 target for the modulation of the excessive oxidase damage induced by overtraining in rat neutrophils. Int J Biol Sci. 7(6): 881-91. doi: 10.7150/ijbs.7.881

Gleeson, M. 2006. Can Nutrition Limit Exercise Induced Immunodepression? Nutr Rev. 64(3): 119-131. doi: 10.1111/j.1753-4887.2006.tb00195.x

450

Halson, S.L., Lancaster, G.I., Achten, J., Gleeson, M., and Jeukendrup, A.E. 2004. Effects of 452 carbohydrate supplementation on performance and carbohydrate oxidation after intensified cycling training. J Appl Physiol. 97(4): 1245-53. doi: 10.1152/japplphysiol.01368.2003 
455 Hohl, R., Ferraresso, R.L.P., De Oliveira, R.B., Lucco, R., Brenzikofer, R., Macedo, D.V.

456 Development and characterization of an overtraining animal model. Med Sci Sports Exerc.

457 2009;41(5):1155-63. doi: 0195-9131/09/4105-1155/0

458

459

Karelis, A.D., Smith, J.W., Passe, D.H., and Péronnet, F. 2010. Carbohydrate Administration

and Exercise Performance: what are the potential mechanisms involved? Sport Med. 40(9):

461

747-63. doi: 10.2165/11533080-000000000-00000

462

463

Kenttä, G., Hassmén, P., and Raglin, J.S. 2001. Training practices and overtraining syndrome

in Swedish age-group athletes. Int J Sports Med. 22(6): 460-5. doi: 10.1055/s-2001-16250

465

Nutr. 7(7): 1-43. doi: 10.1186/1550-2783-7-7

469

470

471

472

Lira, F.S., Rosa, J.C., Pimentel, G.D., Tarini, V.A.F., Arida, R.M., Faloppa, F., et al. 2010. Inflammation and adipose tissue: effects of progressive load training in rats. Lipids Health Dis. 9:109. doi: 10.1186/1476-511X-9-109

473

McAnulty, S.R., McAnulty, L.S., Morrow, J.D., Nieman, D.C., Owens, J.T., and Carper, 475 C.M. 2007. Influence of carbohydrate, intense exercise, and rest intervals on hormonal and 476 oxidative changes. Int J Sport Nutr Exerc Metab. 17(5): 478-90.

477

478 Meeusen, R., Duclos, M., Foster, C., Fry, A., Gleeson, M., Nieman, D., et al. 2013. 479 Prevention, diagnosis, and treatment of the overtraining syndrome: joint consensus statement 
480 of the European College of Sport Science and the American College of Sports Medicine. Med 481 Sci Sports Exerc. 45(1): 186-205. doi: 0195-9131/13/4501-0186/0

482

483

$10.1055 / \mathrm{s}-2008-1025717$

489 Sport Exerc. 37(8): 1283-90. doi: 0195-9131/05/3708-1283/0

502

503

504

Mitchell, J.B. 2013. Ingestion of carbohydrate during recovery in exercising people. Curr Opin Clin Nutr Metab Care. 16(4): 461-5. doi: 10.1097/MCO.0b013e328361c526.

Morgan, W.P., O'Connor, P.J., Sparling, P.B., Pate, R.R., et al. 1987. Psychological characterization of the elite female distance runner. Int J Sport Med. 8(2): 124-31. doi: Morifuji, M., Kanda, A., Koga, J., Kawanaka, K., and Higuchi, M. 2010. Post-exercise carbohydrate plus whey protein hydrolysates supplementation increases skeletal muscle glycogen level in rats. Amino Acids. 38(4): 1109-15. doi: 10.1007/s00726-009-0321-0

Morifuji, M., Kanda, A., Koga, J., Kawanaka, K., and Higuchi, M. 2011. Preexercise ingestion of carbohydrate plus whey protein hydrolysates attenuates skeletal muscle glycogen depletion during exercise in rats. Nutrition. 27(7-8): 833-7. doi: http://dx.doi.org/10.1016/j.nut.2010.08.021

Nieman, D.C., Davis, J.M., Henson, D.A., Gross, S.J., Dumke, C.L., Utter, A.C., et al. 2005. Muscle Cytokine mRNA Changes after 2.5 h of Cycling: Influence of Carbohydrate. Med Sci

Parkington, J.D., Siebert, A.P., LeBrasseur, N.K., and Fielding, R.A. 2003. Differential activation of mTOR signaling by contractile activity in skeletal muscle. Am J Physiol Regul 
505 Integr Comp Physiol. 285(5): 1086-90. doi: 10.1152/ajpregu.00324.2003

506

507 Rogero, M.M., Mendes, R.R., and Tirapegui, J. 2005. Aspectos Neuroendócrinos e

508 Nutricionais em Atletas Com Overtraining. Arq Bras Endocrinol Metabol. 49(3): 359-368.

509 doi: http://dx.doi.org/10.1590/S0004-27302005000300006

510

511 Sapin, M.R., and Tkachuk, M.G. 2005. Thymus recovery after intensive physical exercise

512 under conditions of immunocorrection and without it. Bull Exp Biol Med. 140(5): 568-70.

513 doi: 10.1007/s10517-006-0026-2

514

515 Scharhag, J.Z.R.G.E.N., Meyer, T., Auracher, M., Gabriel, H.H., and Kindermann, W. 2006.

516 Effects of graded carbohydrate supplementation on the immune response in cycling. Med Sci

517 Sports Exerc. 38(2): 286-92. doi: 10.1249/01.mss.0000191437.69493.d4

518

519

520

stress. Med Sci Sports Exerc. 32(2): 317-331. doi: 0195-9131/00/3202-0317/0

521

522 Smith, L.L. 2004. Tissue trauma: the underlying cause of overtraining syndrome? J strenght

523 Cond Res. 18(1): 185-93. doi: http://dx.doi.org/10.1519/00124278-200402000-00028

524

525 Song, S., Shimada, N., and Anderson, P. 1963. Ortogonal diameters in the analysis of muscle 526 fiber size and form. Nature. 200: 1220-1. doi:10.1038/2001220a0

527 
528 Terra, R., Silva, S.A.G., Pinto, V.S., and Dutra, P.M.L. 2012. Effect of exercise on the 529 immune system: response, adaptation and cell signaling. Rev Bras Med do Esp. 18(3): 208530 214. doi: http://dx.doi.org/10.1590/S1517-86922012000300015

531

532 Toone, R.J., Betts, J.A. 2010. Isocaloric carbohydrate versus carbohydrate-protein ingestion 533 and cycling time-trial performance. Int J Sport Nutr Exerc Metab. 20(1): 34-43.

534

535 Towbin, H., Staehelin, T., Gordon, J. 1979. Electrophoretic transfer of proteins from 536 polyacrylamide gels to nitrocellulose sheets: procedure and some applications. 537 Biotechnology. 24(9): 145-9. doi: 10.1073/pnas.76.9.4350

538

Van Loon, L.J., Saris, W.H., Kruijshoop, M., and Wagenmakers, A.J. 2000. Maximizing postexercise muscle glycogen synthesis: carbohydrate supplementation and the application of amino acid or protein hydrolysate mixtures. Am J Clin Nutr. 72(1): 106-11.

542

543

544

Walsh, M., Cartwright, L., Corish, C., et al. 2011. The body composition, nutritional knowledge, attitudes, behaviors, and future education needs of senior schoolboy rugby players in Ireland. Int J Sport Nutr Exerc Metab. 21(5): 365-76.

Woods, J.A., Ceddia, M.A., Zack, M.D., Lowder, T.W., and Lu, Q. 2003. Exercise training 548 increases the näive to memory T cell ratio in old mice. Brain Behav Immun. 17(5): 384-92. 549 doi: 10.1016/S0889-1591(03)00030-8

550

551 Xiao, W., Chen, P., and Dong, J. 2012. Effects of Overtraining on Skeletal Muscle Growth 552 and Gene Expression. Int J Sport Med. 33(10): 846-53. doi: 10.1055/s-0032-1311585 
554 Yan, Z., Spencer, M., and Katz, A. 1992. Effect of low glycogen on glycogen synthase in 555 human muscle during and after exercise. Acta Physiol Scand. 145: 345-52. doi: $556 \quad 10.1111 / \mathrm{j} .1748-1716.1992 . t b 09374 . x$

557

558 Zivković, I.P., Rakin, A.K., Petrović-Djergović, D.M., Kosec, D.J., and Mićić, M.V. 2005. 559 Exposure to forced swim stress alters morphofunctional characteristics of the rat thymus. J 560 Neuroimmunol. 160(1-2): 77-86. doi: http://dx.doi.org/10.1016/j.jneuroim.2004.11.002 
562 Table 1 - Weight of Animals, Organs and Peritoneal Fat after the OT induction protocol.

\begin{tabular}{ccccc}
\hline & & C & EX & EX-CHO \\
\hline Weight & $\mathrm{G}$ & $436,7 \pm 74,9$ & $316,0 \pm 22,4^{* *}$ & $323,6 \pm 30,03^{* *}$ \\
Gastrocnemius & $\mathrm{G}$ & $2,06 \pm 0,27$ & $1,67 \pm 0,06^{* *}$ & $1,74 \pm 0,23^{* *}$ \\
Gastrocnemius/ Body & $\mathrm{mg} / \mathrm{g}$ & $4,89 \pm 0,27$ & $5,32 \pm 0,36$ & $5,39 \pm 0,48^{*}$ \\
Weight & & & & \\
Thymus & $\mathrm{mg}$ & $0,339 \pm 0,14$ & $0,124 \pm 0,03^{* *}$ & $0,179 \pm 0,05^{* * \#}$ \\
Thymus/ Body Weight & $\mathrm{mg} / \mathrm{g}$ & $0,79 \pm 0,22$ & $0,39 \pm 0,11^{* *}$ & $0,56 \pm 0,21^{* *}$ \\
Peritoneal Fat & $\mathrm{G}$ & $30,03 \pm 11,44$ & $7,46 \pm 2,89^{* *}$ & $8,29 \pm 3,86^{* *}$ \\
Peritoneal Fat / Body & $\mathrm{g} / \mathrm{g}$ & $0,06 \pm 0,01$ & $0,02 \pm 0,0^{* *}$ & $0,025 \pm 0,01^{* *}$ \\
Weight & & & & \\
\hline
\end{tabular}

563

564 Data are presented as the mean \pm standard deviation. Weights of gastrocnemius, thymus and 565 peritoneal fat are expressed as an absolute weight $(\mathrm{g})$ and relative to the total body weight 566 (mg/g or $\mathrm{g} / \mathrm{g}) .{ }^{*} \mathrm{p}<0.05$ compared to $\mathrm{C} ;{ }^{*} \mathrm{p}<0.001$ compared to $\mathrm{C}$ in a one-way ANOVA; \# $567 \mathrm{p}<0.05$ between groups EX and EX-CHO, Student's $t$ test. 
571 Table 2 - Muscle damage markers, catabolic/anabolic hormonal activity and oxidative stress

572 after the overtraining induction protocol.

\begin{tabular}{ccccc}
\hline & & $\mathbf{C}$ & $\mathbf{E X}$ & EX-CHO \\
\hline CK & $\mathrm{U} / \mathrm{L}$ & $903,1 \pm 767$ & $1090,7 \pm 671,1$ & $1264 \pm 745,7$ \\
Cortisol & $\mathrm{ng} / \mathrm{mL}$ & $30,33 \pm 9,35$ & $30,66 \pm 8,3$ & $27,63 \pm 10,21$ \\
Testosterone & $\mathrm{ng} / \mathrm{mL}$ & $1,70 \pm 0,8$ & $0,65 \pm 0,42^{* * *}$ & $0,55 \pm 0,3^{* * *}$ \\
Testosterone/Cortisol & - & $0,05 \pm 0,03$ & $0,02 \pm 0,01$ & $0,02 \pm 0,01$ \\
MDA & $\mu \mathrm{M}$ & $0,5 \pm 0,10$ & $0,8 \pm 0,10^{* *}$ & $0,8 \pm 0,14^{* *}$ \\
\hline
\end{tabular}

574 Data are presented as the mean \pm standard deviation. $\mathrm{C}=$ sedentary control $(\mathrm{n}=6) ; \mathrm{EX}=$

575 exercise group $(\mathrm{n}=9)$; EX-CHO = exercise group with carbohydrate supplementation $(\mathrm{n}=$

576 11); $\mathrm{CK}=$ creatine kinase; $\mathrm{MDA}=$ malondialdehyde $* \mathrm{p}=0.01$ compared to $\mathrm{C} ; * * * \mathrm{p}=$

5770.001 compared to C (one-way ANOVA with Tukey's post hoc test).

578

579 
580 Figure 1 - Procedure for the experimental protocol for overtraining.

581

582

Figure 2 - Results of performance tests conducted along the overtraining induction protocol.

583

584

Pr2. Two-way ANOVA with Tukey's post hoc analysis.

589

590

591

592 with Dunn's post hoc analysis.

596

597 respectively) after the overtraining induction protocol.

600

601

602

$\mathrm{C}=$ control group $(\mathrm{n}=7) ; \mathrm{EX}=$ exercise group $(\mathrm{n}=7) ; \mathrm{EX}-\mathrm{CHO}=$ exercise group with carbohydrate supplementation $(\mathrm{n}=7)$. Data are shown as the mean \pm standard deviation. ${ }^{*} \mathrm{p}=0.01$ compared to $\mathrm{C} ;{ }^{* *} \mathrm{p}=0.0001$ compared to $\mathrm{C}, * * * \mathrm{p}<0.0001$ compared to $\mathrm{C}$. One-way 604 ANOVA with Tukey's post hoc test. 


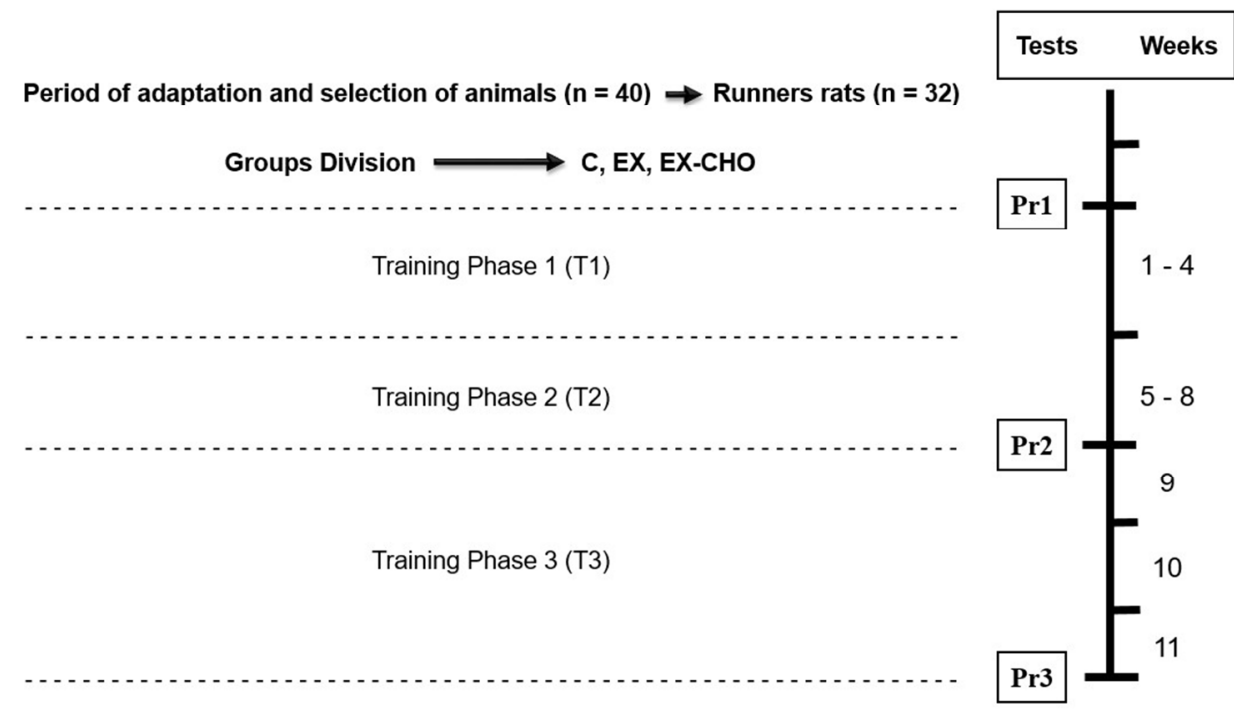

Figure 1 - Procedure for the experimental protocol for overtraining. $95 \times 54 \mathrm{~mm}(300 \times 300 \mathrm{DPI})$ 


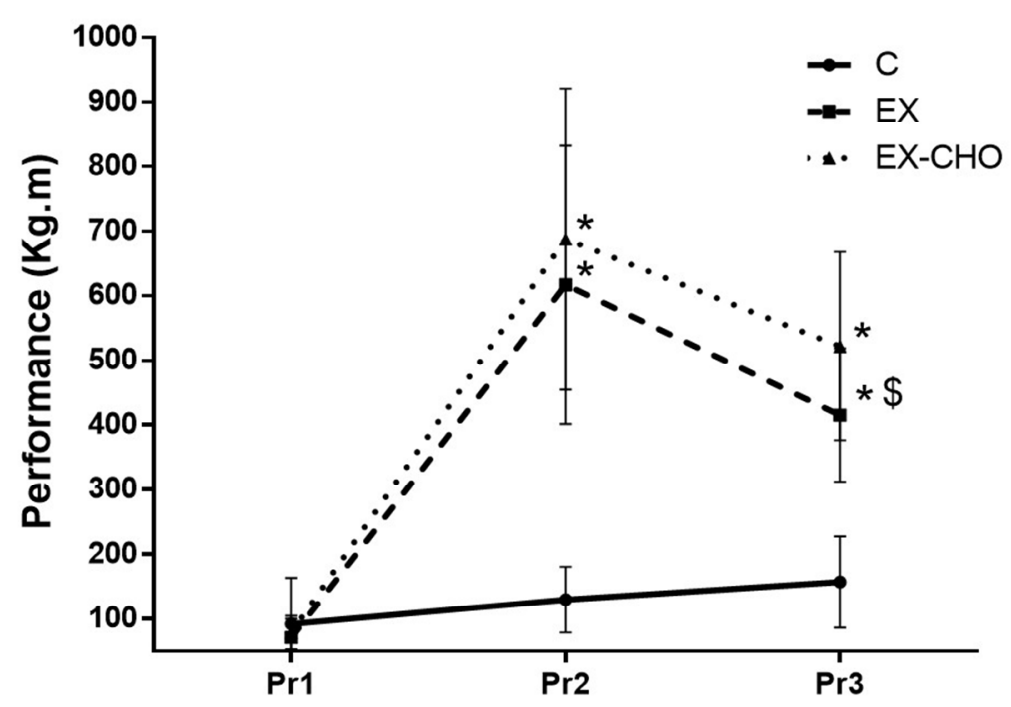

Figure 2 - Results of performance tests conducted along the overtraining induction protocol.

$\operatorname{Pr} 1, \operatorname{Pr} 2$ and Pr3 = Performance of animals before experimental protocol, at the 9th week and at the 11 th week, respectively. $\mathrm{C}=$ control group $(n=9) ; E X=$ exercise group $(n=10)$; EX-CHO = exercise group with carbohydrate supplementation $(n=13)$. Data are mean and standard deviation. $*=p<0.05$ compared to $C$ in the same Pr; $\$=p<0.05$ compared to EX in Pr2. Two-way ANOVA with Tukey's post hoc analysis. $100 \times 55 \mathrm{~mm}(300 \times 300 \mathrm{DPI})$ 


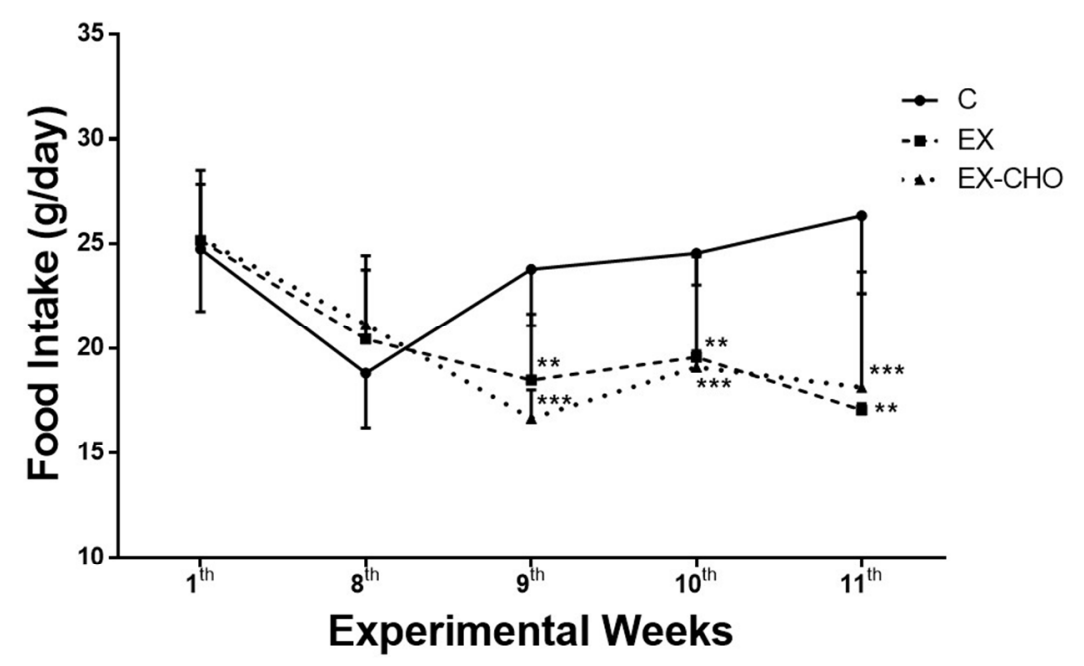

Figure 3 - Food consumption during the overtraining induction protocol.

$C=$ control group $(n=9) ; E X=$ exercise group $(n=10) ; E X-C H O=$ exercise group with carbohydrate supplementation $(n=13)$. Data are mean and standard deviation. $*=p<0.01$ compared to $C$ in the 8 th week; $* *=p<0.001$ compared to $C$ in the 8th week. Friedman test with Dunn's post hoc analysis.

$101 \times 55 \mathrm{~mm}(300 \times 300 \mathrm{DPI})$ 

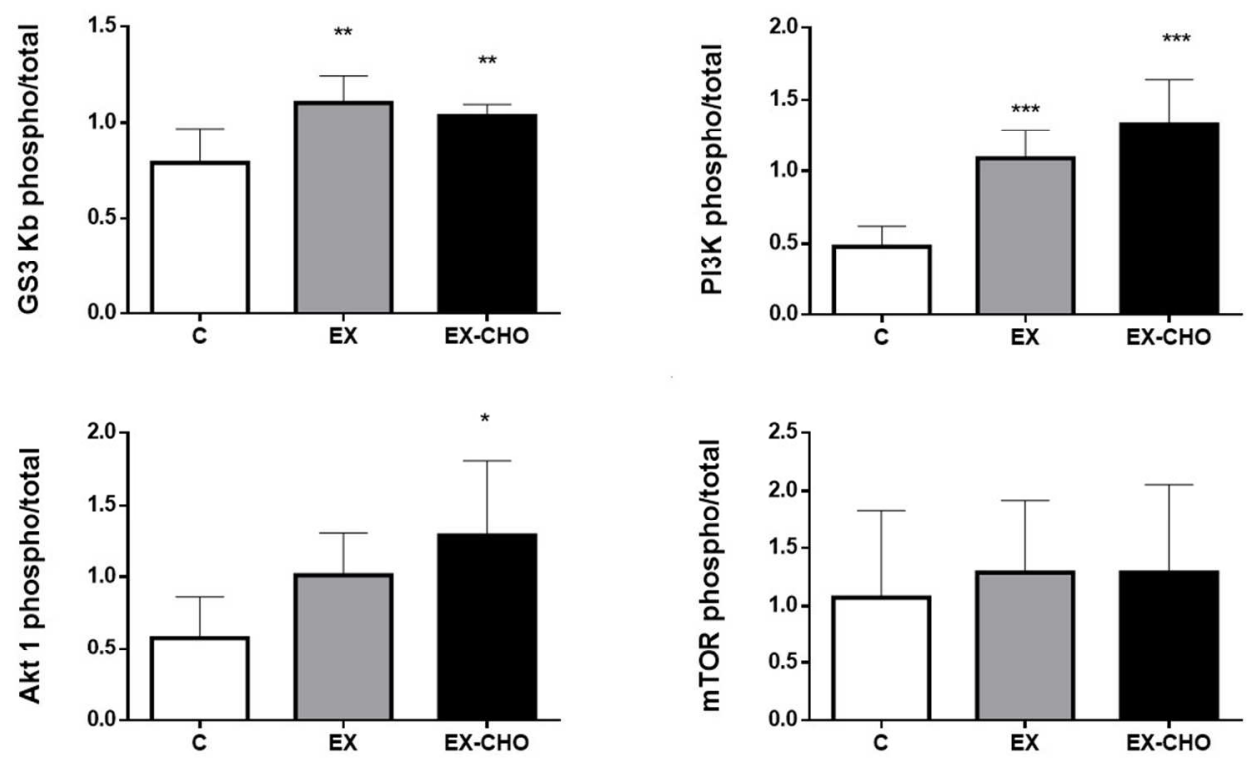

Figure 4 - Activity of enzymes associated with glycogen synthesis (GS3Kb, panel A) and protein synthesis in the gastrocnemius muscle (PI3K, mTOR, and Akt 1 ; panels $B, C$ and $D$, respectively) after the overtraining induction protocol.

$C=$ control group $(n=7) ; E X=$ exercise group $(n=7) ; E X-C H O=$ exercise group with carbohydrate supplementation $(n=7)$. Data are shown as the mean \pm standard deviation. ${ }^{*} p=0.01$ compared to $C$; $* * p=0.0001$ compared to $\mathrm{C}, * * * \mathrm{p}<0.0001$ compared to $\mathrm{C}$. One-way ANOVA with Tukey's post hoc test.

$94 \times 56 \mathrm{~mm}(300 \times 300$ DPI $)$ 